\title{
Self-Compensating Excitation of Fluxgate Sensors for Space Magnetometers
}

\author{
Cerman, Alec; Merayo, José M.G.; Brauer, Peter; Primdahl, Fritz
}

Published in:

IEEE Instrumentation and Measurement Technology Conference Proceedings, 2008. IMTC 2008.

Link to article, DOI:

10.1109/IMTC.2008.4547387

Publication date:

2008

Document Version

Publisher's PDF, also known as Version of record

Link back to DTU Orbit

Citation (APA):

Cerman, A., Merayo, J. M. G., Brauer, P., \& Primdahl, F. (2008). Self-Compensating Excitation of Fluxgate Sensors for Space Magnetometers. In IEEE Instrumentation and Measurement Technology Conference Proceedings, 2008. IMTC 2008. IEEE. https://doi.org/10.1109/IMTC.2008.4547387

\section{General rights}

Copyright and moral rights for the publications made accessible in the public portal are retained by the authors and/or other copyright owners and it is a condition of accessing publications that users recognise and abide by the legal requirements associated with these rights.

- Users may download and print one copy of any publication from the public portal for the purpose of private study or research.

- You may not further distribute the material or use it for any profit-making activity or commercial gain

- You may freely distribute the URL identifying the publication in the public portal 


\title{
Self-Compensating Excitation of Fluxgate Sensors for Space Magnetometers
}

\author{
A. Cerman, J.M.G. Merayo, P. Brauer, F. Primdahl \\ Danish National Space Center, Technical University of Denmark, Elektrovej Bldg. 327, Lyngby, Denmark \\ Phone: +45 4525 3594, E-mail: ac@space.dtu.dk
}

\begin{abstract}
The paper presents design and implementation of the new self-compensating excitation circuitry to the new generation of highprecise space vector magnetometers. The application starts with complex study including design of new robust model of the non-linear inductor leading to investigation of the most crucial points, contimuous by design of the self-compensating excitation unit and concludes with unit complex testing and application to the magnetometer. The application of the self-compensation of the excitation decreases temperature drift of the magnetometer offset caused by the temperature drift of the sensor (dominant source of the offset drift) by factor of 7 .
\end{abstract}

Keywords - Space instrumentation, fluxgate magnetometer, selfcompensation, intelligent systems

\section{INTRODUCTION}

For last several years our laboratory has been involved in several dedicated satellite magnetic field mapping missions (Ørsted [1], SAC-C and CHAMP launched in 1999, 2000 and 2000 , respectively), where we supplied the main on-board measurement instrument - the high precision fluxgate magnetometer. Although these instruments proved excellent behavior, some of the parameters tend naturally to drift due to hard environmental conditions of the space, therefore a scalar magnetometer is also part of the payload for calibration purpose. At present, the autonomy of the vector magnetometer instrument onboard is limited to the basic operation, whereas the calibration is done onground. Derivation and implementation of self-correction algorithms and electronic circuits, which may guarantee the invariance of the instrument parameters during the whole satellite mission, is of special interest and the aim of this paper. The main motivation is cost reduction of pre-, in- and post-fight calibration. This is very important for incoming multi-satellite ESA SWARM mission [2].

The aim of the presented work is to implement an electronic circuitry allowing on-board self-compensation of the magnetometer offset temperature drift caused by the temperature change of the sensor excitation circuitry. The magnetometer electronics is inside the satellite body and thermostated. However, in order to avoid an influence of the parasitic magnetic field generated by the satellite itself, the sensor is mounted on the several meters long boom and thus fully exposed to the space environment. The sensor includes an excitation resonant tank, which parameters are sensitive to the temperature variation and which is the main source of the magnetometer offset drift as demonstrated in this paper.

\section{EXCITATION RESONANT TANK}

The most important consideration for the fluxgate excitation is that the ferromagnetic core must be deeply saturated in order to suppress the sensor perming and to decrease the sensor noise [3]. To ensure such a high excitation current and also in order to keep the power consumption of the excitation circuitry small enough for portable or satellite applications, the tuning capacitor is usually connected in parallel to the sensor excitation winding and this resonant tank is supplied from $\mathrm{AC}$ current source (see Fig. 1). The resulting excitation current is in shape of narrow peaks - lower trace of Fig. 2.

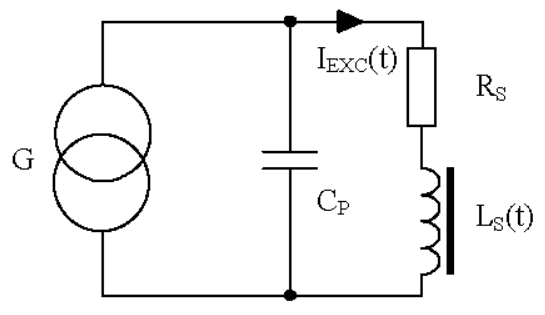

Fig. 1. Fluxgate sensor excitation resonant tank

The magnetometers built at Danish National Space Center (DNSC, former Ørsted-DTU) use all-even harmonic shortcircuited (current-output) detection of the fluxgate sensor output [4]. The resulting sensor output signal is in shape of narrow peaks which amplitude linearly corresponds to measured magnetic field and which duration corresponds to saturation of the sensor core, i.e. they are strictly in phase with excitation current peaks. The sensor output peaks are detected by use of the switching-mode phase-sensitive detector. Both, the excitation control signal and the detector control signal, are usually generated from common frequency reference and their mutual phase-shift is set to a fixed value (see Fig. 2).

The stability of the resonant tank is affected by variations on the its parameters. As it was presented by Nielsen et al [5], these changes do not affect only amplitude of the excitation current, but also its phase. Authors of [5] also identify that the change of the resonant tank phase (i.e. phase between sensor output signal and detector control signal, as it was discussed above) can be correlated to on the magnetometer offset. 


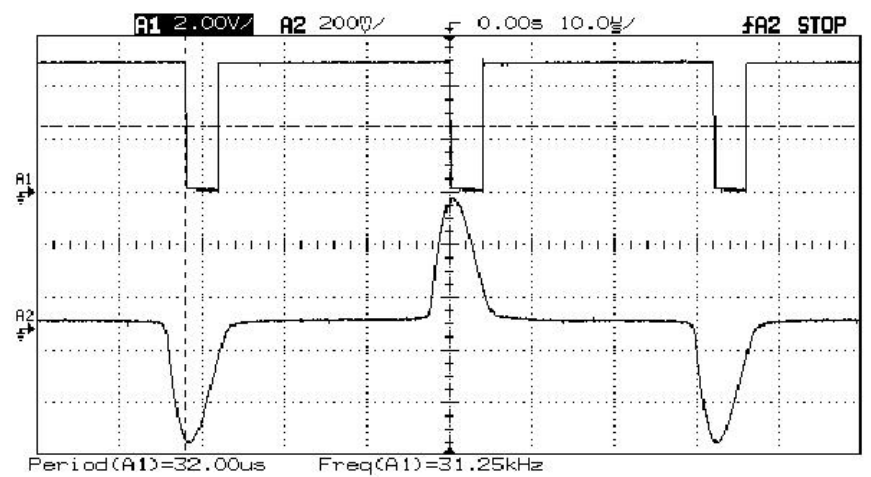

Fig. 2. Excitation current (lower trace) in phase with phase-sensitive detector control signal (upper trace)

\section{NEW MODELING METHOD AND VERIFICATION OF THE EXCITATION RESONANT TANK}

Recently several analyses of the resonant tank behavior were published [5][6][7]. All of these analyses are based on two well-defined states (inductions) of the sensor excitation coil:

- $\mathrm{L}_{\mathbb{I N}}$ for $\mathrm{I}_{\mathrm{EXC}}=0$

- $\mathrm{L}_{\mathrm{SAT}}$ for $\mathrm{I}_{\mathrm{EXC}}>\mathrm{I}_{\mathrm{SAT}}$

Furthermore, all of these analysis uses a sine-wave supply current, so the resulting shape of the excitation coil current $\mathrm{I}_{\mathrm{EXC}}(\mathrm{t})$ is then composition of two sine-wave currents component with small amplitude for non-saturated state and component with high amplitude for saturated state. Such a type of analyze can be used for calculation of parallel resonant capacitor $C_{P}$ and peak resonant current $\mathrm{I}_{\mathrm{EXC}-\mathrm{MAX} \text {, however it }}$ cannot be used for study of the phase-stability of the resonant tank.

In order to be able study also the phase-stability, the OrCAD PSpise simulation was used for study of the sensor excitation tank behavior. The PSpice offers modeling of nonlinear magnetic materials based on the Jiles-Atherton model [8], however, this model is not suitable for modeling of the fluxgate excitation for two reasons:

- the model is defined by the material parameters, which are not provided by the manufacturer,

- the model exhibited convergence problems with deep saturation, which is necessary for proper function of the fluxgate sensor.

Due to this, we have devised a new model based on the Analog Behavioral Modeling (ABM) using the general relation between the coil voltage and current.

$$
i(t)=\frac{1}{L} \int u(t) d t
$$

The integration constant $1 / \mathrm{L}$ is modified according to the core saturation, i.e. according to amplitude of the current flowing through the inductor. The inductance as function of the certain excitation current can be easily measured on the real sensor or calculated from the core material parameters and winding parameters. The values of inductances are stored in the look-up table E1. The integration is realized by use of the voltage controlled current source G1 charging capacitor $\mathrm{C} 1$. The voltage on the capacitor controls the second voltage controlled current source G2. The hysteresis is not included in the model, because the core material of the sensor is amorphous with very low hysteresis and the core ribbon wound inside the ring-shape bobbin is additionally stress annealed in order to obtain a hard ribbon axis magnetic anisotropy, which reduces hysteresis virtually to zero. Detailed description of used core material and construction of the sensor can be found in [9].

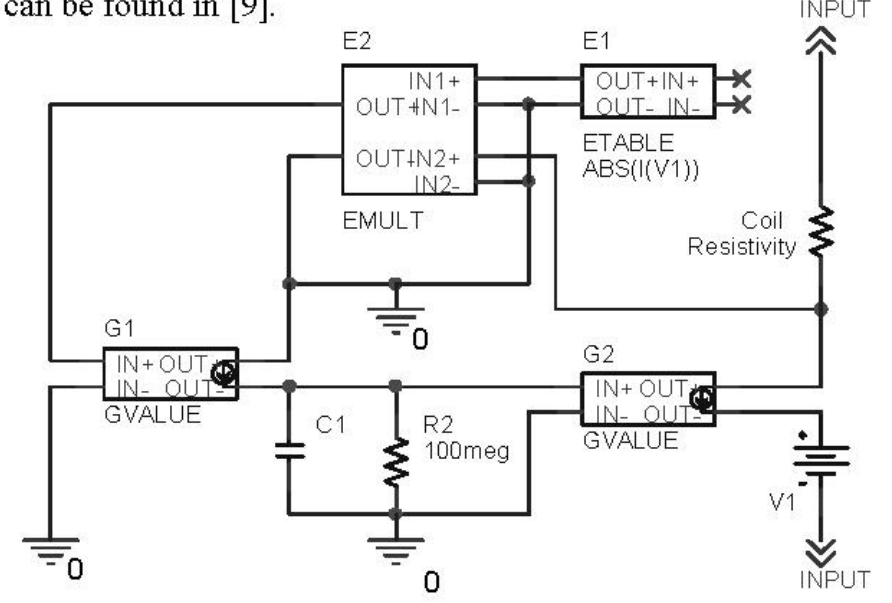

Fig. 3. New simple and robust model of non-linear inductor

The main advantage of using PSpise for simulation is possibility to simulate the resonant tank together with certain excitation driver and using any shape of the excitation current. An example of resulting shape of the simulated excitation current is shown in Fig. 4. Left side of the plot represents startup of the excitation. The dependence of the phase-shift to the temperature of the excitation coil (change of the coil resistivity according to the temperature) is shown in Fig. 5.

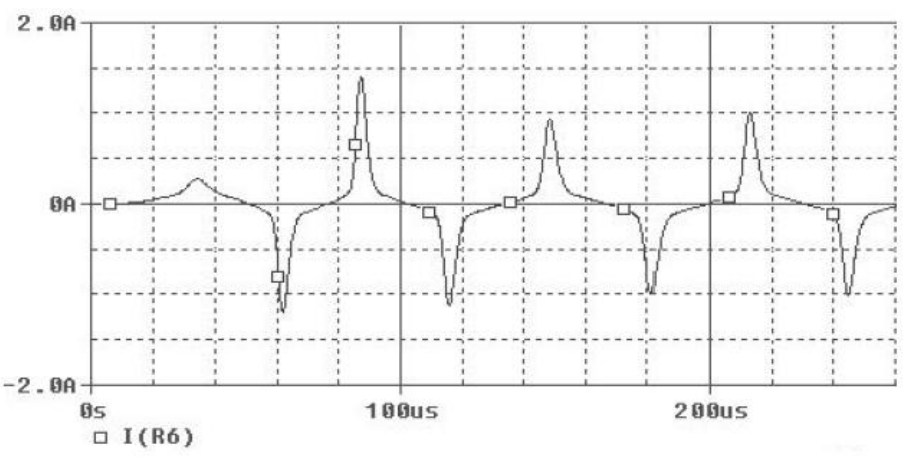

Fig. 4. Time plot of the simulated excitation current

To prove the model correctness, the simulated excitation circuitry was realized. The sensor was placed in the temperature chamber, which was inside the 6-layer magnetic shielding and the phase between the excitation control signal and the excitation current was measured by a lock-in amplifier. The measured phase-shift (Fig. 6) showed very similar 
behavior compared to the simulation (Fig. 5), which proves the correctness and reliability of the model. Also all other parameters such a shapes and amplitudes of the excitation current and excitation voltage corresponded to the simulation.

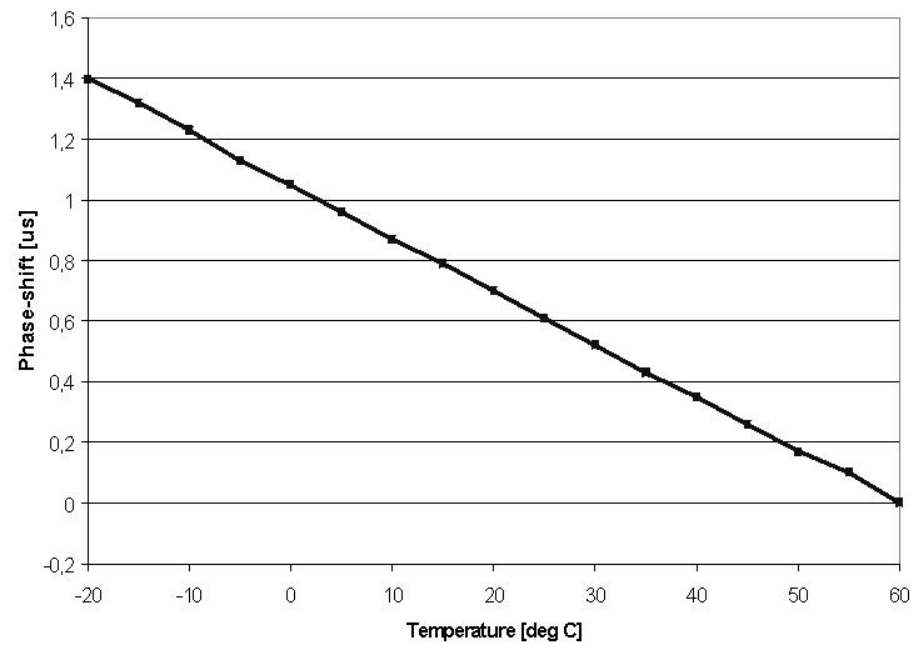

Fig. 5. Phase-shift between the excitation control signal and excitation current - result of simulation

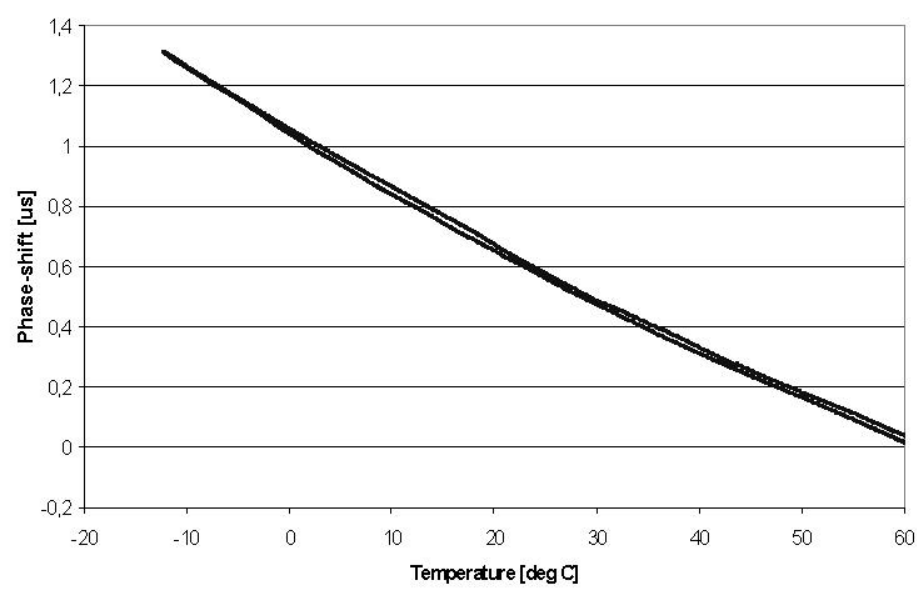

Fig. 6. Phase-shift between the excitation control signal and excitation current - measurement $\mathrm{n}$ real magnetometer

Main goals of the presented modeling method:

- New simple and robust model of non-linear inductor suitable for modeling of fluxgate excitation circuitry,

- Simple adaptation of the model to different sensor parameters,

- The method allows to study not only the amplitudes of the excitation voltage and current, but also their shapes and phases related to the reference signal,

- Method allows to model the resonant tank together with exact excitation circuitry including its parasitic parameters (PSpice models of transistors, amplifiers and passive components),

- The method allows studying of influence of different shapes of excitation signals to the sensor excitation.
Complex simulation of the resonant tank behavior proved that the dominant source of the resonant tank phase unstability is the serial resistivity of the excitation coil and the simulation was verified by measurement on the real magnetometer.

\section{SELF-COMPENSATING EXCITATION CIRCUITRY}

The dominant source of the magnetometer offset temperature drift is due to the phase shift between excitation current and synchronous detector control signal. As described above by the simulation of the excitation circuit, the main source of this phase-shift is temperature dependence of the excitation coil resistivity. The compensation of the resistivity itself would be cumbersome, therefore another method has been devised, namely the compensating of the phase-shift of excitation control circuitry dynamically.

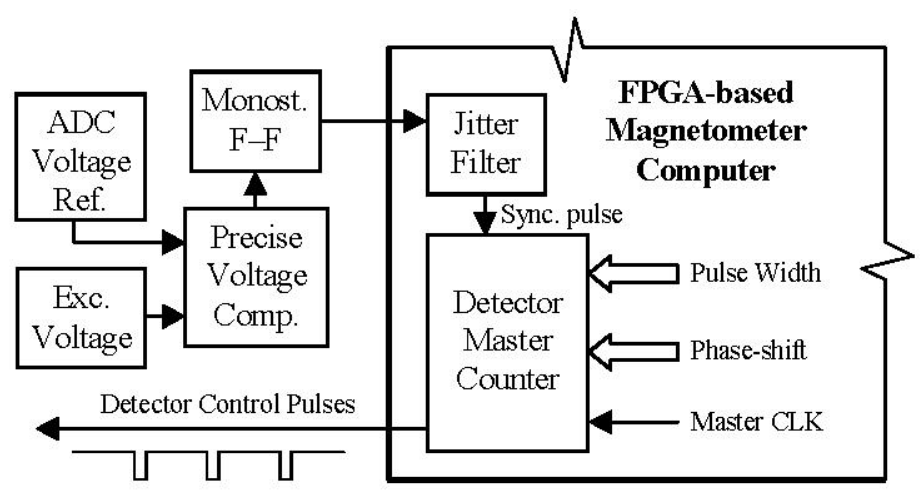

Fig. 6. Principle of self-compensating excitation circuitry

Currently, the fluxgate sensor excitation and detection control circuitry is based on digital counters dividing a clock frequency from a crystal oscillator, hence the phase-shift is set to a fixed value. Thus, the main idea of automatic compensation is to synchronize the free running counter with excitation current. The detection of the excitation current is difficult since the resonant capacitor is mounted inside the sensor head, and the sensor is placed several meters away from the electronics in a long boom from the satellite body. Therefore, the excitation voltage phase shift, which is in phase with the excitation current, is used as input for the synchronization. The excitation voltage is compared to a certain reference voltage, and therefore the circuitry will generate a short synchronization pulse, which is used as an asynchronous reset for the free running counter and thus the counter will be synchronized with the excitation voltage. The compensation circuitry consists of high-precise high-stable voltage comparator comparing fixed reference voltage to excitation voltage, a temperature stable monostable flip-flop, the digital excitation control signal and detector control signal generator, which is a part of the FPGA-based magnetometer computer (see Fig. 6).

Since the synchronization pulses are connected to the asynchronous reset input of the counter, i.e. the counter can be stopped at any time independently of the master clock, some of 
the clock periods can be missed. In case the asynchronous reset pulse fluctuates about the active edge of the clock signal, the phase jitter of the counter output (i.e. of the PSD control signal) can be observed. The jitter corresponds to fluctuation about one period of master clock, as it is demonstrated in Fig. 7 (counter is sensitive to the rising edge of the clock and it is preset to the binary value 3 in this example; the period of OUT signal is longer about one period of CLK for "ignored edges periods" compare to normal period).

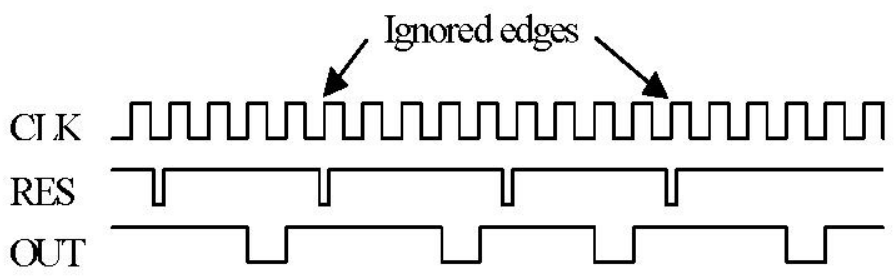

Fig. 7. Origin of a jitter of the PSD control signal

The influence of such a jitter to the magnetometer output data was tested and it proved to be an additional source of the noise. Change of the phase-shift setting about one period of the master clock corresponds to the least significant bit (LSB) of the input preset value of the counter. Thus the fluctuation of the LSB was used for study of the jitter influence to the magnetometer parameters.
The counter was not synchronized and sensor was held at the constant temperature. The LSB of the counter one preset input was connected to the TTL compatible output of the precise generator. The output of the magnetometer was studied using dynamic signal analyzer.

During the experiment it was found out that the amplitudes of the jitter noise are depended on the frequency of the jitter and also on the phase-shift between the sensor excitation control signal and PSD control signal. Fig. 8 shows dependence of the amplitude of 1st-harmonics of the noise on the frequency in the range from $0.1 \mathrm{~Hz}$ to $500 \mathrm{~Hz}$ and on the phase-shift in range of $\pm 1.375 \mu$ s from the basic set phase-shift of the magnetometer. The lowest leakage was observed for phase-shift of $125 \mathrm{~ns}$. For this phase-shift the amplitude of the 1 st-harmonic of the noise is less than $20 \mathrm{pT}_{\mathrm{RMS}}$ for the frequencies of the jitter below $100 \mathrm{~Hz}$ and less $10 \mathrm{pT}_{\mathrm{RMS}}$ for the frequencies of the jitter below $10 \mathrm{~Hz}$. Because the magnetometer usually includes the output low-pass filter with cut-off frequency of few tens of $\mathrm{Hz}$, which was disconnected during the measurement, the noise out of this magnetometer base-band will be suppressed by this filter.

In order to suppress the additional noise caused by the jitter, the synchronization pulses are not used for compensation of every period of the PSD control signal. The pulses pass through the decimation filter which function is to reduce the frequency of the compensation (see Fig. 6).

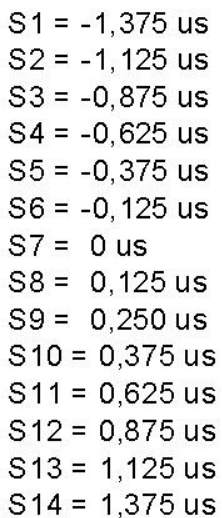

S1 $=-1,375$ us

$S 2=-1,125$ us

$S 6=-0,125$ us

$\mathrm{S} 7=0 \mathrm{us}$

$S 8=0,125$ us

s9 $=0,250$ us

$\mathrm{S} 10=0,375$ us

$S 11=0,625$ us

$S 13=1,125$ us

$\mathrm{S} 14=1,375$ us

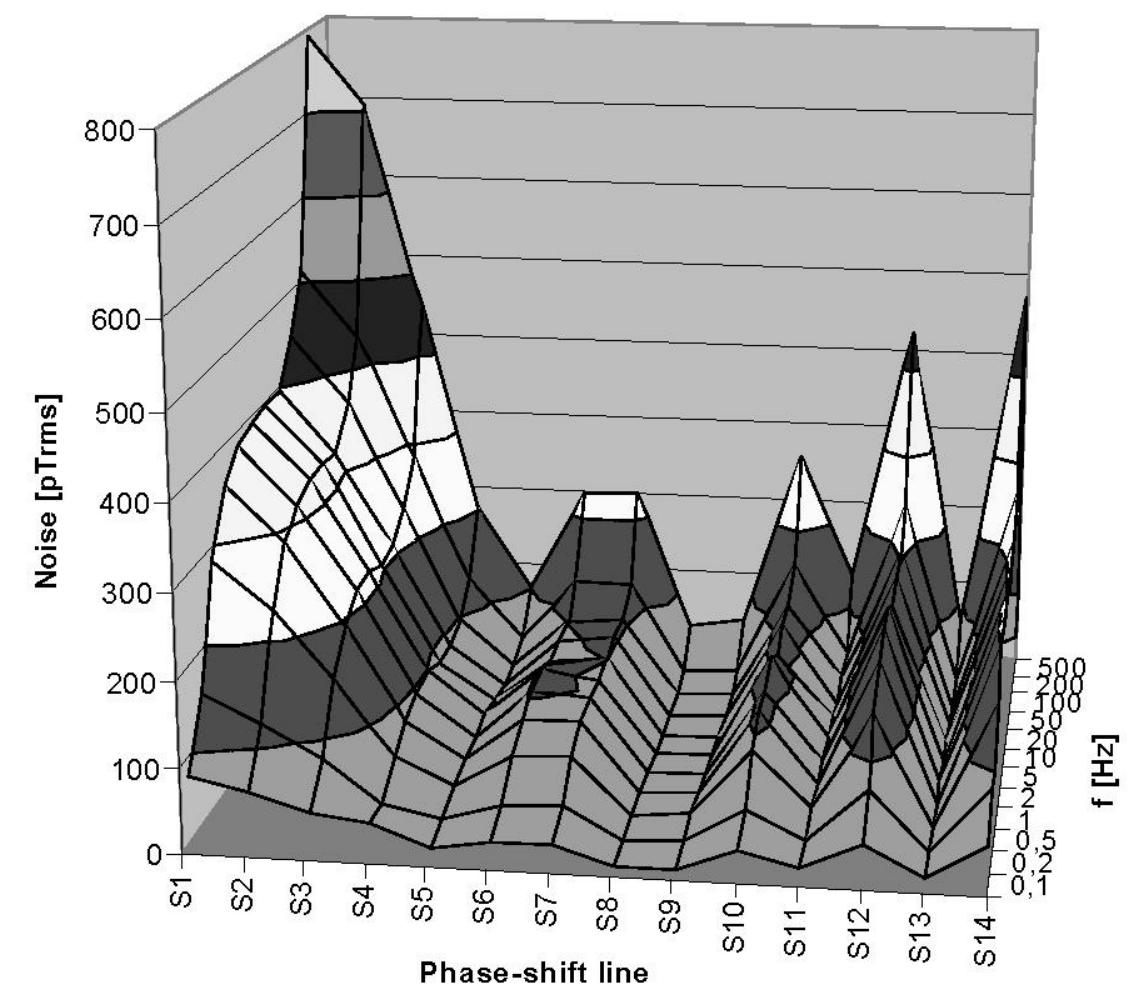

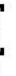

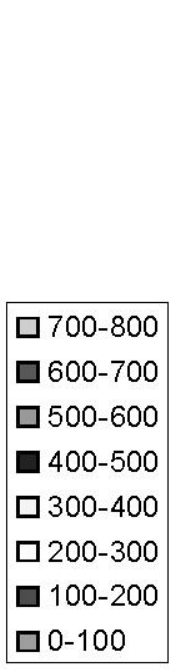

$\square 700-800$
$\square 600-700$
$\square 500-600$
$\square 400-500$
$\square 300-400$
$\square 200-300$
$\square 100-200$
$\square 0-100$ 


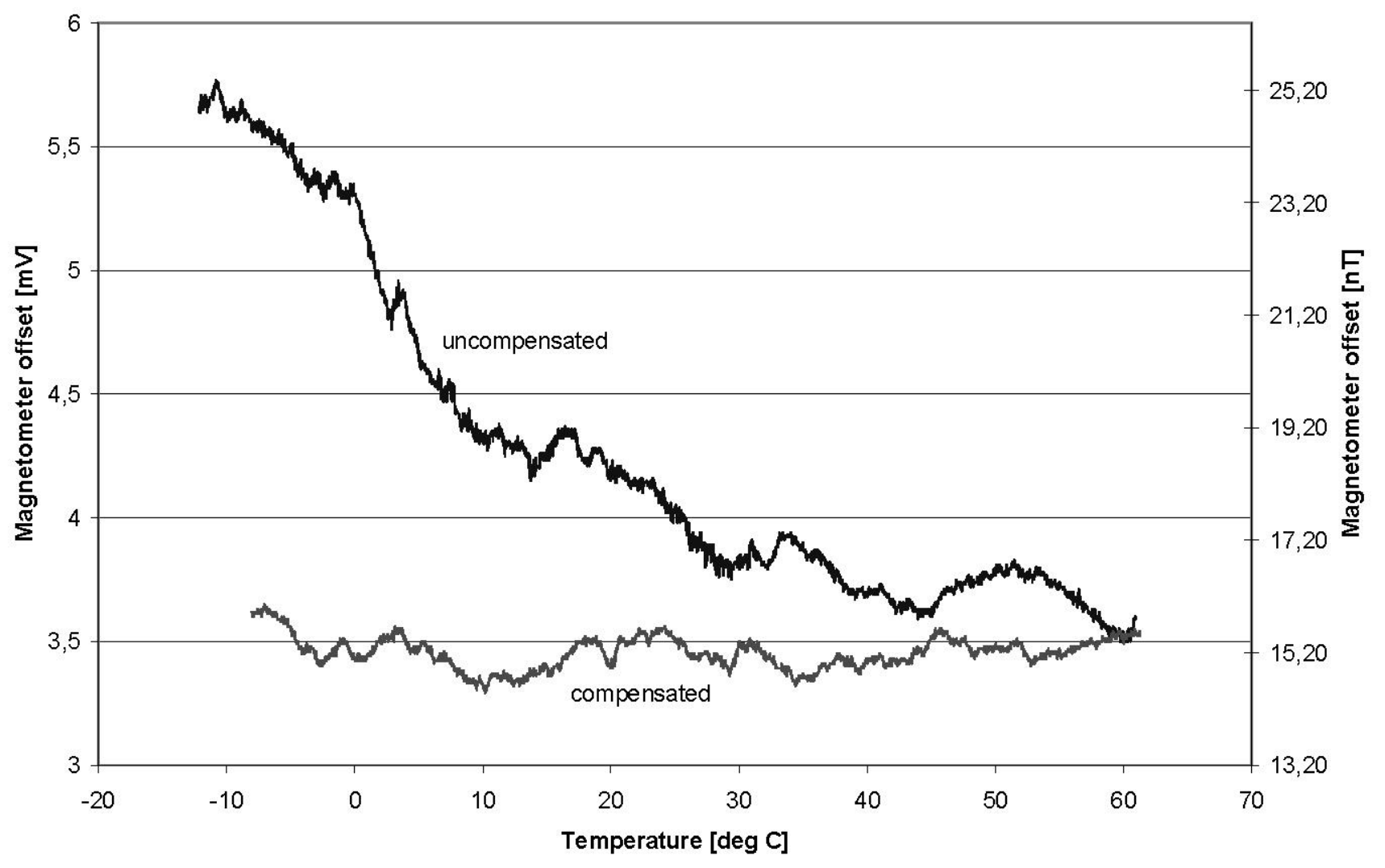

Fig. 9. Efficiency of the self-compensating excitation circuitry to the decreasing of the magnetometer offset temperature drift

\section{EFFICIENCY OF THE SELF-COMPENSATING EXCITATION}

The temperature testing of the automatic compensation circuitry proved that the circuitry is capable to keep the phaseshift between sensor excitation and the detector control signal in range of \pm 1 period of master clock signal.

The efficiency of the compensation is shown in Fig. 9. Compared to the drift of $9.8 \mathrm{nT}$ of the uncompensated magnetometer for the temperature range $+60^{\circ} \mathrm{C}$ to $-13^{\circ} \mathrm{C}$, the drift of the offset is within the range $\pm 0.5 \mathrm{nT}$ for the same temperature range. Resultantly, the compensation circuitry compensates the magnetometer offset drift caused by the change of the excitation resonant tank by factor of 7 .

\section{NEW GENERATION OF HIGH PRECISE SPACE VECTOR MAGNETOMETER}

A new generation of the high precise space vector magnetometers was recently developed at DNSC. The magnetometer is going to be tested together with stellar compass (also developed at DNSC) onboard the ESA technology demonstrator Proba-2 (launch is planned to the end of 2007). The magnetometer is being currently modified for the most dedicated magnetic field mission SWARM planned for launch in 2010. The magnetometer is shown in Fig. 10.
Parameters of the new generation of the space magnetometers currently being realized at DNSC [10]:

- Measuring range $\pm 65536.0 \mathrm{nT}$

- Resolution $0.0625 \mathrm{nT}$ (corresponding to 21 bits)

- Intrinsic sensor noise $15 \mathrm{pT}_{\mathrm{RMS}}(0.1-10 \mathrm{~Hz})$

- Intrinsic sensor noise $6.6 \mathrm{pT}_{\mathrm{RMS}} / \sqrt{\mathrm{Hz}} @ 1 \mathrm{~Hz}$

- Intrinsic electronics noise $50 \mathrm{pT}_{\mathrm{RMS}}(0.1-10 \mathrm{~Hz})$

- Intrinsic electronics noise $20 \mathrm{pT}_{\mathrm{RMS}} / \sqrt{\mathrm{Hz}} @ 1 \mathrm{~Hz}$

- ADC sampling rate $50 \mathrm{~Hz}$, linear phase filter

- Offset temperature drift $\sim 0 \mathrm{nT} /{ }^{\circ} \mathrm{C}$ (sensor)

- Offset temperature drift $\sim 0.1 \mathrm{nT} /{ }^{\circ} \mathrm{C}$ (electronics)

- Scale factor temp. drift $\sim 10 \mathrm{ppm} /{ }^{\circ} \mathrm{C}$ (sensor)

- Scale factor temp. drift $\sim 2 \mathrm{ppm} /{ }^{\circ} \mathrm{C}$ (electronics)

Electronics box and sensor mechanical parameters:

- Electronics box size $100 \times 100 \times 50 \mathrm{~mm}$

- Electronics box weight $650 \mathrm{~g}$

- Cold redundant (consists of two identical magnetometers, two identical DC-DC power supplies and cross-trapping board)

- Sensor diameter of $\varnothing 82 \mathrm{~mm}$

- Sensor weight $350 \mathrm{~g}$

- Magnetometer power consumption. less than $1.25 \mathrm{~W}$ 


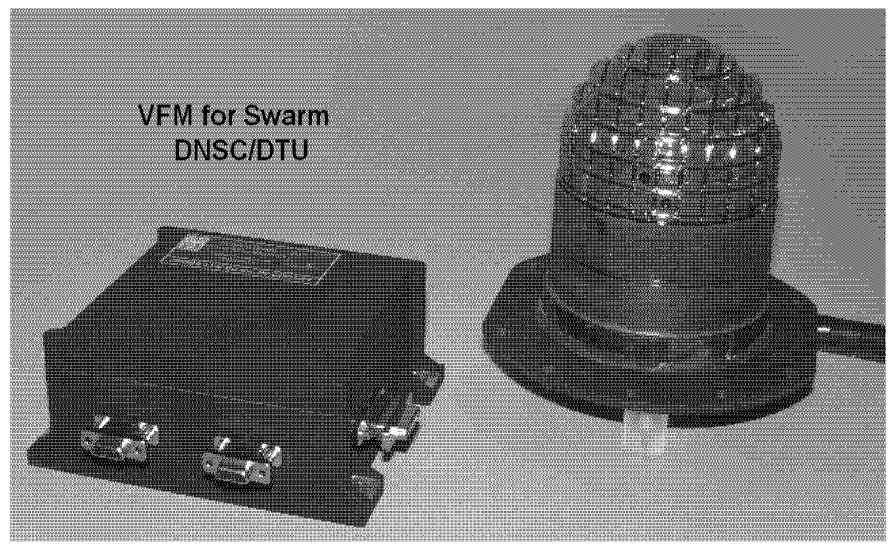

Fig. 10. New generation of the high precise space vector magnetometers with compact-spherical-coil designed at DNSC and involved in ESA Proba2 and ESA SWARM missions

\section{CONCLUSION}

An implementation of the self-compensating excitation unit was presented. The design of the unit started with complete simulation, when the new robust PSpice based model of the non-linear inductor was designed and used for study of the excitation resonant tank behavior. With using the results of simulation verified by measurements on the real magnetometer the new self-compensating excitation was designed. A potential problem of additional noise caused by possible jitter of the PSD control signal was deeply studied. However, with correct setting of the parameters of the compensation, the level of the noise caused by jitter is less than $10 \mathrm{pT}_{\mathrm{RMs}}$ in the baseband of the magnetometer. Further more, the jitter is additionally suppressed by application of decimation filter. Finally, an application of the self-compensating excitation decreases the dominant source of the magnetometer temperature offset drift by factor of 7 .

The new generation of high precise space vector field magnetometers currently being realized at DNSC was also shortly introduced.

\section{ACKNOWLEDGEMENT}

The presented work is a part of the CALAUMAG project focused on increasing of the high-precise space magnetometers autonomy and supported by European Commission under the Marie Curie Individual Fellowship (grant MEIF-CT-2006024724).

\section{REFERENCES}

[1] T. Neubert et al, "Orsted Satellite Captures High-Precision Geomagnetic Field Data", EOS, Transactions, AGU, vol. 82, pp 87-88, 2001

[2] N. Olsen et al, "Swarm - The Earth's Magnetic Field and Environment Explorers", Special issue of Earth Planets Space, Vol. 58 (No. 4), 2006

[3] P. Ripka et al: Magnetic Sensors and Magnetometers, Artech House, Boston, 2001
[4] F. Primdahl, J.R. Petersen, C. Olin, K. Harbo Andersen: The shortcircuited fluxgate output current, J. Phys. E.: Sci. Instrum. 22, 1989, pp. 349-354

[5] O.V.Nielsen, J.R.Petersen, F.Primdahl, P.Brauer, B.Hernando, A.Fernandez, J.M.G.Merayo, P.Ripka: Development, construction and analysis of the 'Ørsted' fluxgate magnetometer, Meas. Sci. Technol. 6 (1995), 1099-1115

[6] P. Ripka, W. Hurley, "Excitation tuning of fluxgate sensors", IMTC 2002, Anchorage, Alaska, pp. 677-680

[7] P. Ripka, W. Hurley, "Switching-mode fluxgate", Transducers, paper EU90, Boston, 2003, pp. 1283-1286

[8] D.C. Jiles, D.L. Atherton, "Theory of ferromagnetic hysteresis", JMMM, vol. 61,1986 , pp. $48-60$

[9] Nielsen, O.V., P. Brauer, F. Primdahl, T. Risbo, J.L. Jørgensen, C. Boe, C. Deyerle and S. Bauereisen: A high-precision triaxial fluxgate sensor for space applications: Layout and choice of materials, Sensors and Actuators A Physical, vol. 59, p. 168-176, 1997

[10] J. M. G.Merayo, Jørgensen, J. L., Friis-Christensen, E., Brauer, P., Primdahl, F., Jørgensen, P. S., Allin, T. H., Denver, T.; The Swarm Magnetometry Package, in Small Satellites for Earth Observation, edited by Rainer Sandau, Hans-Peter Röser and Amoldo Valenzuela, 2008, ISBN: 978-1-4020-6942-0 